\title{
Graphene and graphene oxide as nanomaterials for medicine and biology application
}

\author{
Subhashree Priyadarsini ${ }^{1} \cdot$ Swaraj Mohanty $^{2} \cdot$ Sumit Mukherjee $^{1} \cdot$ Srirupa Basu $^{1} \cdot$ Monalisa Mishra $^{1}$
}

Received: 2 March 2018 / Accepted: 23 May 2018 / Published online: 7 June 2018

(c) The Author(s) 2018

\begin{abstract}
Graphene- and graphene oxide-based nanomaterials have gained broad interests in research because of their unique physiochemical properties. The 2D allotropic structure allows it to be used in various biological fields. The biomedical applications of graphene and its composite include its use in gene and small molecular drug delivery. It is further used for biofunctionalization of protein, in anticancer therapy, as an antimicrobial agent for bone and teeth implantation. The biocompatibility of the newly synthesized nanomaterials allows its substantial use in medicine and biology. The current review summarizes the chemical structure and biological application of graphene in various fields.
\end{abstract}

Monalisa Mishra

mishramo@nitrkl.ac.in

1 Neural Developmental Biology Laboratory, Department of Life Science, National Institute of Technology (NIT), Rourkela, Odisha, India 769008

2 Bachelor of Technology (B. Tech), Department of Biotechnology, Gandhi Institute of Engineering and Technology (GIET), Biju Patnaik University of Technology (BPUT), Gunupur, Rourkela, Odisha 769015, India 
Graphical abstract

\section{Graphene Nanoparticle}

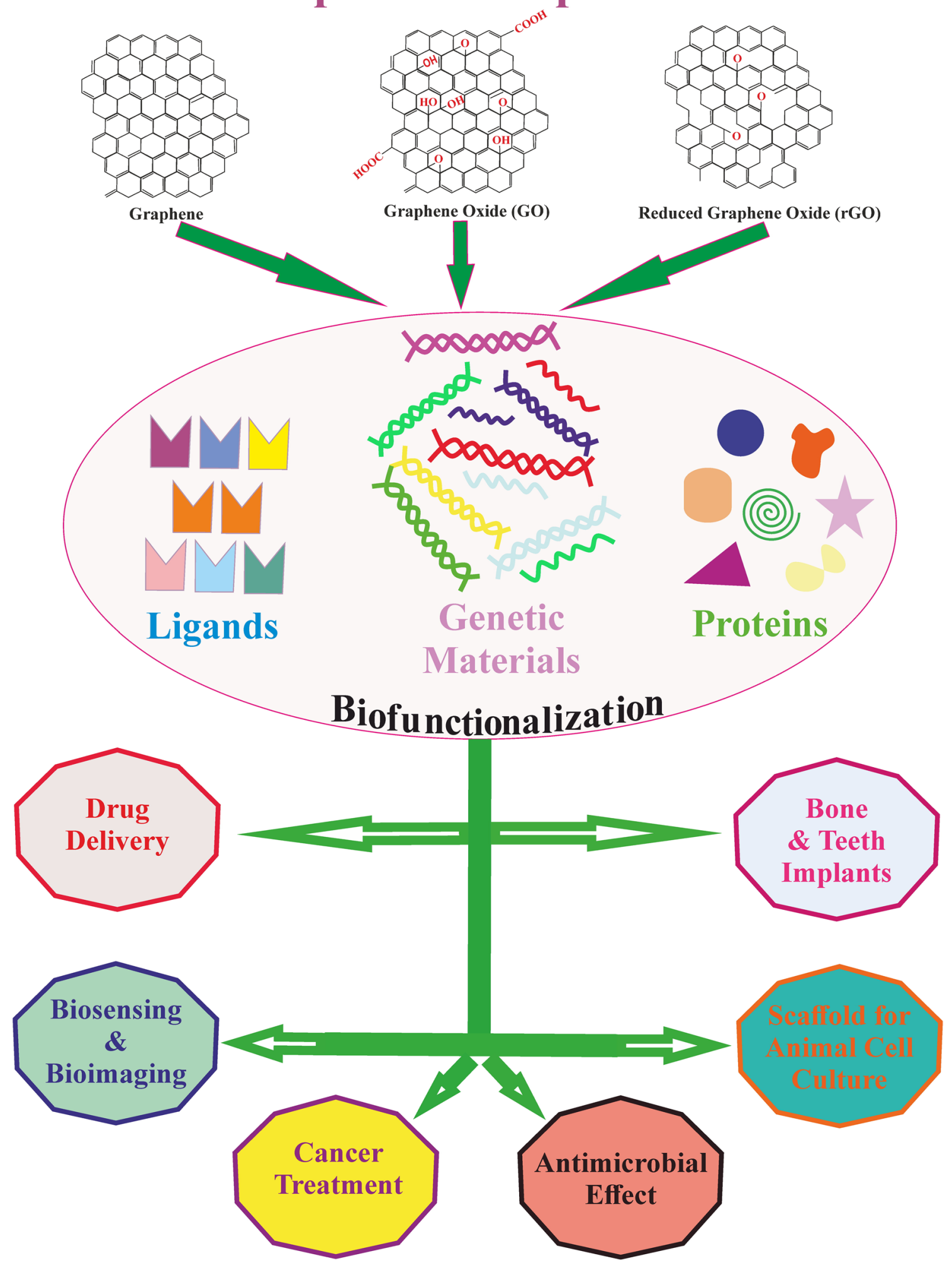

Keywords Graphene - Graphene oxide · Reduced graphene $\cdot$ Nanoparticles $\cdot$ Biomedical application 


\section{Introduction}

Graphene is formed by a thick sheet of carbon atoms bonded by $\mathrm{sp}^{2}$ hybridization arranged in a hexagonal array. It has gained immense interest in various fields due to its unique electrochemical properties which include high thermal conductivity, high current, density, chemical inertness, optical transmittance and very high hydrophobicity [1,2]. It is the simplest form of carbon and the thinnest material produced so far [3]. It exists as few layers of graphite. $\mathrm{X}$-ray diffraction technique reveals the crystal structure of graphene as a closely packed honeycomb-like structure [4] (Fig. 1). The graphene family includes members such as reduced graphene oxide (rGO), graphene oxide (GO) [5], graphene sheets and layered graphenes such as few layered graphenes and multilayered graphene (MLG) [6, 7].

Besides its availability in nature, its wide use has led us to synthesize it by two common methods: (1) the top-down and (2) the bottom-up method. In the top-down approach, layers of graphite are simply separated to get the graphene layer. But to do this, van der waals interaction between the layers need to be broken [8]. However, there are several challenges with this method such as defects in the surfaces may occur during the preparation of sheets of graphene and the discrete sheets cumulate subsequently. Generally, the top-down approach offers low yield and the process is very tedious [8]. In the bottom-up approach, carbon molecules which are procured from different origins are used as building blocks [9]. This approach is also not suitable for making graphene sheets with a huge surface area. At the time of fabrication of graphene, the most conventional method to synthesize graphene was the mechanical cleavage of graphite which produces high-quality, defect-free graphene [10]. An effective alternative method is chemical vapour deposition (CVD) $[11,12]$. It was observed that the above procedures are time-consuming and produce very low yields, but in the case of mechanical cleavage methods it helps in the effective and full exploitation of these materials [13]. The alternative method which is scalable, cost-effective and gives excessive yield is exfoliation of graphite or its derivatives like GO [14].

$\mathrm{GO}$ is obtained from a highly oxidized form of graphene molecule by using many strong oxidizing agents. Particularly, GO, due to its excellent surface functionability, amphiphilicity, aqueous appearance, fluorescence quenching ability and surface-enhanced Raman's scattering property, is chemically exfoliated from other graphene derivatives [15]. These exceptional characteristics of GO is due to the small $\mathrm{sp}^{2}$ carbon domains which are enclosed by $\mathrm{sp}^{3}$ domains and the hydrophilic functional groups containing oxygen due to its distinctive chemical structure [16]. Hummer's method is widely used to synthesize GO, as it includes oxidation of graphite by mixing the solution of graphite, potassium permanganate and sulphuric acid [17]. This exfoliation in solvents with sonication results in graphite salts, which act as a precursor for GO. The thermal and chemical reduction process of GO converts it to a graphene analog [14]. It has a wide application for filtration purposes, as this thin membrane has the property of filtering harmful gases but is permeable to water. GO is a mass of solid prepared by the process of oxidation of graphite through various chemical processes, which enlarge the interlayer spacing and the base planes. It can be peeled off in a solution to convert it to a monolayer or a few-layer form of GO [5].

rGO is synthesized from GO by thermal (photothermal), chemical (photochemical), microwave or different bacterial as well as microbial methods by reducing its oxygen amount (Fig. 2). It is widely used in the field of electronics to manufacture conductive ink circuits and fabrication of electronic devices [18]. The layered graphene is synthesized by the stacking of two-dimensional sheet-like GO in a small number (2-10), but the individual scrap should still maintain its high aspect ratio. This MLG has
Fig. 1 a Chemical structure. b Crystal structure of graphene compound

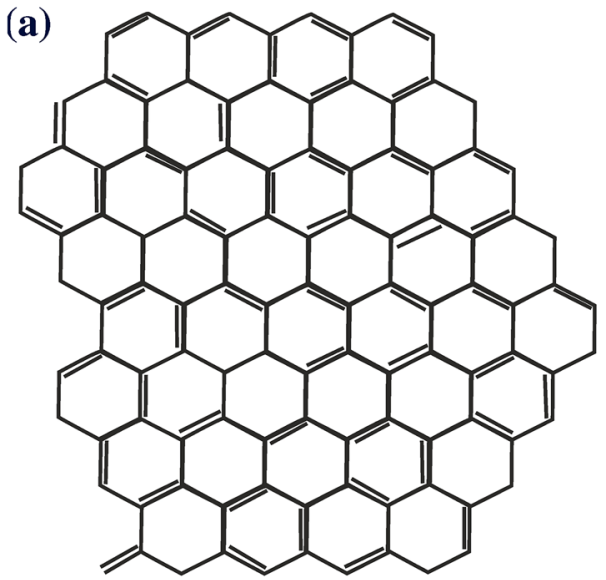

(b)

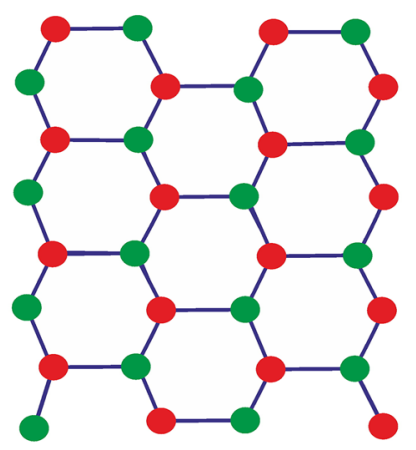

Represents the carbon atoms Represents the carbon atoms Bonds joining the carbon atoms 


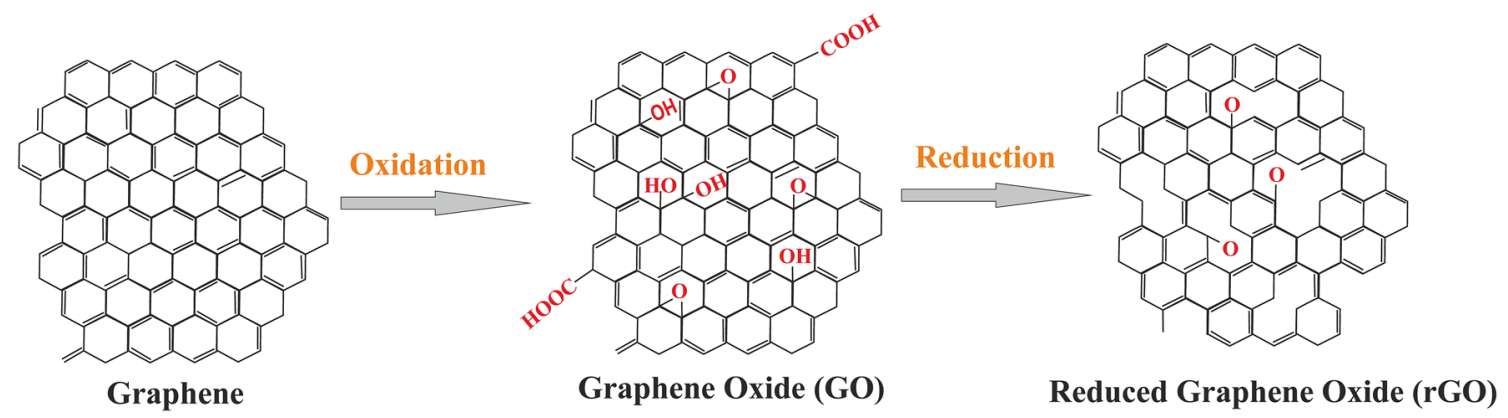

Fig. 2 Conversion of graphene into GO and rGO

a wide application in the supplementation of mechanical engineering and in the manufacture of composite materials [6]. Among all the forms, GO has recently gained immense interest in biomedical applications.

GO has unique intrinsic physical as well as chemical properties. Some of the chemical properties include large surface area, functionality containing oxygen, better conductivity and good biocompatibility. The chemical property allows it to be used in bioimaging, biosensing and hypothermia capabilities [19]. 2-D nanosheet graphene contains a single layer of carbon atom arranged hexagonally to increase the surface area, diameter, thickness, stiffness and conductivity. Graphene has specific catalytic, mechanical, electronic, thermal, biological and optical properties [7, 20-22], which allow it to be used for biomolecule recognition, bioassays, molecular medicine and small molecular drug delivery. The biocompatibility and quick functionalization make graphene an assuring platform in tissue engineering [23], molecular drug delivery [24], cancer treatment [25], biosensing [26], and bioimaging [27]. Graphene-based materials are used in the field of bone repair or organ regeneration. Both GO and rGO are utilized in osteogenic stem cells to study [28-30] chondrogenesis [31], adipogenesis [32], epithelial genesis [32], myogenesis, cardiomyogenesis $[33,34]$ and neurogenesis [35].

Graphene is utilized as a substrate interfacing with different cells and biomolecules. Modification of graphene enhances its compatibility, selectivity and solubility in a biological system [36]. Graphene is used for drug delivery [37], biomolecule recognition, bioassays and in molecular medicine. Graphene and its materials are extensively applied in antibacterial compositions [25, 38, 39], biosensing [40], energy storage [41], catalysis [42] and tissue scaffolds [28]. In this review, we have listed various uses of graphene and graphene-based materials in the biomedical field.

\section{Biomedical applications of graphene}

Graphene has been in the forefront of research since the past few years. Development of new methods of graphene synthesis has made this material easily available in the market. Along with graphene, its derivatives such as GO and rGO have gained much more interest in their application (Fig. 3).

\section{Biofunctionalization with proteins}

Graphene interacts with the protein, the building block of the body. It interacts either with the secondary structure, functional group or by physical adsorption. The charge status of the functional group is dependent on the environment such as ionic strength and $\mathrm{pH}$ value of the buffer, since the positive or negative charge of the proteins depends on the presence of carboxylate and protonated amino group, respectively [25]. The variation in the surface charge density of functional groups containing oxygen on GO determines its preparation and storage. The GO-oxygen containing groups, makes it acceptable for immobilization of biocatalysts with no surface adjustments and no coupling reagents [43]. Further, to monitor the protein absorption by using the channel of graphene as electrolyte gate, field effect transistor was

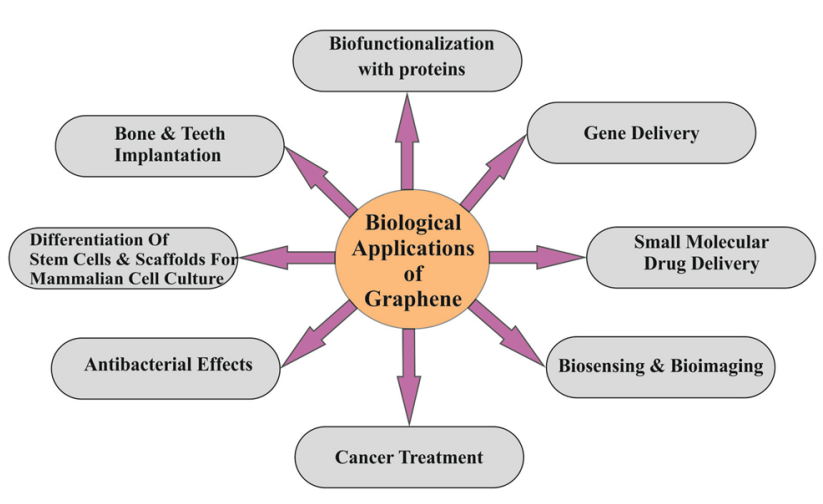

Fig. 3 Biological application of graphene 
built [25]. GO has been conjugated with gold-Ab and modified the traditional surface plasmon resonance. GO provides a larger surface area and abundant oxygen molecules as a functional group benefiting the method of immobilization and detection sensitivity [44]. Go-based biosensors have been also used to detect ssDNA, living cells and metal ions [45]. Thus, GO is used to immobilize several proteins. Lysozyme and horseradish peroxidase enzymes can be exhausted suddenly on the surface of GO [46]. Also, a microbial protein hydrophobin is used in the functionalization of GO [25]. Introduction of various metals such as $\mathrm{Au}, \mathrm{Ag}, \mathrm{Pd}$ and Pt with the graphene nanosheet has been reported [47]. The immobilization of enzymes on inorganic materials has proved to be a fruitful application, improving its stability under various conditions [48]. Nanomaterials such as magnetic $\mathrm{GO}$ are synthesized by covalent binding of amino $\mathrm{Fe}_{3} \mathrm{O}_{4}$ onto $\mathrm{GO}$ and were used to immobilize laccase [49]. Compared to free laccase and immobilized laccase, the one immobilized showed higher thermal stability and various $\mathrm{pH}$ values [49]. Functional forms of graphene-immobilized naringinase have shown high isoquercitrin production. $92.24 \pm 3.26 \%$ yield was found in microchannel reactor after 20 mins [50]. The $\mathrm{Vm} / \mathrm{Km}$ kinetic parameter showed an increase to 1.9 -fold and a 1/3rd decreased reaction time in a batch reactor. The result shows when the sheets of graphene are immobilized with an enzyme, the specificity increases and shows a mild catalytic characteristic so that the enzyme can be reused [49]. GO is applied for immobilization in the case of $\beta$-amylase. Functionalized sheets of GO were also modified on a matrix causing Fenugreek immobilization [51]. The affecting factors were analysed using SPR, SEM and TEM that showed an immobilization efficiency of $84 \%$ [51].

.Green fluorescent protein (EGFP) is a protein of 293 amino acids $(32.7 \mathrm{kDa})$ and emits bright green fluorescence radiation when exposed to blue towards UV light. EGFP is biologically inert $[52,53]$, and thus extensively used in the biological field to identify cells and tissue having target gene expression [54, 55]. EGFP-tagged graphene has been synthesized as EGFP-rGO and used to study lactate dehydrogenase ( $\mathrm{LDH}$, which is present in all cells) leakage, a suitable index to check cytotoxicity based on the absence of integrity of membrane which mainly focuses on necrosis [56]. Incubation of cells with EGFP-rGO does not change its morphology, suggesting it as nontoxic for the cell. Thus, it can be used as a marker to study cytotoxicity and identification of cells or region of tissues having an expression of target genes [57]. It is used with highly specific proteins, for instance, biotin/avidin interaction or antigen antibody-antigen interaction.

GO-protein interaction is applied in protein crystallization. Obtaining a nucleus and controlling it as a prolific method for diffracting crystals of protein and solving its structure with the help of X-ray crystallography. Involving GO has proved to be fruitful in nucleation and graphene sheets offer a wider heterogeneity of surface along with multiple sized, 'pockets (interparticle)' where crystals of protein are able to nucleate [47].

\section{Biofunctionalization with DNA}

ssDNA along with graphene serves as a good surfaceenhanced laser desorption/ionization time-of-flight mass spectrometry analysis platform; also, graphene embedded with DNA is used to form different nanoparticles and other biosystems. Thiol GO-DNA sheets can make a two-dimensional bionano interface to accumulate gold nanoparticles maintaining its optical properties [25]. FRET biosensor, based on graphene, includes fluorescein amidite-labelled ssDNA that are absorbed on the GO sheet. The application also includes molecular beacon fabricated to graphene-based FRET biosensors enhancing its DNA detection property.

\section{Gene delivery}

Gene delivery is a method of introducing foreign DNA into the cell. It is an alternative approach to cure various genetic diseases. Modified GO is used for gene delivery purposes. Polyethylenimine (PEI) modifies the surface of GO sheets and thus makes it ready for cellular gene delivery through covalent conjugation and electrostatic interaction [58] for plasmid DNA (pDNA) stacking. GO is attached covalently to the linear chain [35] and branched chain [59]. PEI is thus used for high-quality transfection effectiveness containing low cytotoxicity than pDNA/PEI complexes. Thus, it has an upper hand over PEI/pDNA complexes. As of date, chitosancomplexed GO (CS-GO) has been integrated. This complex is used for productive delivery of anticancer medication and plasmid DNA stacked individually simultaneously by electrostatic and $\pi-\pi$ interaction [60].

\section{Small molecule drug delivery}

The presence of the proteolytic enzymes present in the cytoplasm often interferes in the drug delivery process. GO is used in case of effective gene and drug delivery acting as a carrier (Fig. 4). The functional group $(\mathrm{COOH}$ and $\mathrm{OH})$ of $\mathrm{GO}$ allows it to conjugate with various polymers and biomolecules (ligand, DNA, protein).

Approaches include its functionalization with cationic polymer, for example PEI [24]. It is used as a non-viral gene vector as it can strongly interact with the negatively charged phosphate ions of DNA and RNA [24]. It makes transfection easy and efficient, improves cell selectivity and reduces cell toxicity. The use of PEI-functionalized GO delivery of antiapoptotic family protein $\mathrm{Bcl}$-2-targeted 


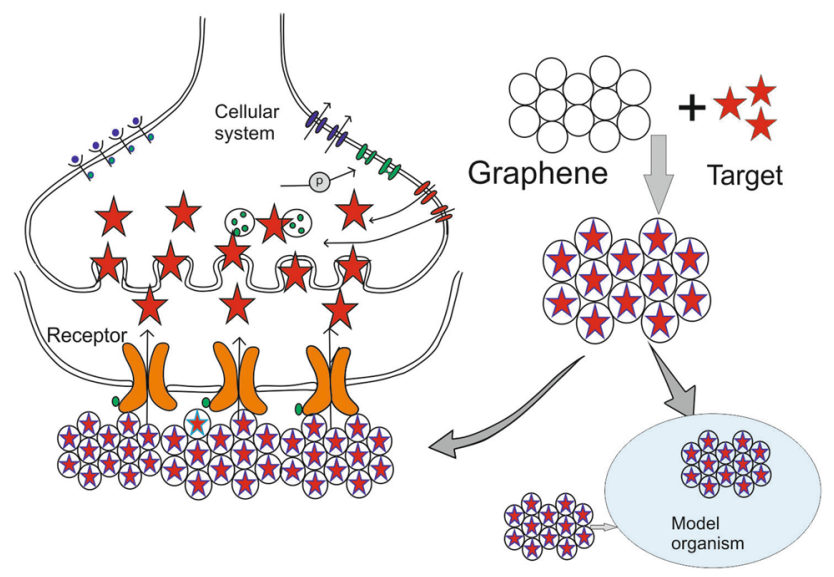

Fig. 4 Graphene as a carrier for target (gene or small molecular drug) delivery

siRNA and anticancer drug DOX exhibited a synergistic effect offering a higher transfection efficacy with decreased cytotoxicity of PEI and enhanced anticancer efficacy [61]. A photochemically controlled gene delivery carrier has also been developed where PEI of low molecular weight and rGO are conjugated with polyethylene glycol (PEG) of hydrophilic nature and was confirmed to be stable with plasmid DNA by physiochemical assays [57]. FeO nanoparticles provided GO with multifunctionality and multimodality for assorted organic and medicinal applications [62]. Antiinflammatory drug delivery of ibuprofen has been reported by applying chitosan-containing GO [35].

The unmodified basal plane sites of graphene that has free surface $\pi$ electrons are hydrophobic and are capable of forming $\pi-\pi$ interactions for loading drug as well as covalent modifications [63, 64]. Some of the drug delivery occurs due to the change in temperature, $\mathrm{pH}$, light and salt concentration. Polymers can detect the change in the surroundings and the drug is delivered. GO biopolymers are sensitive towards $\mathrm{pH}$ and thus also used as a transporter for smart drug delivery. For instance, doxorubicin (DOX)-GO compound indicated the appearance of DOX from GO which is $\mathrm{pH}$ sensitive because of DOX's higher solvency at low $\mathrm{pH}$ [65]. Considering this point of interest, $\mathrm{pH}$-sensitive delivery was effectively exhibited in case of DOX and camptothecin by utilizing folic acid consisting of nano-GO (NGO), called FA-NGO to treat tumours [44]. Ibuprofen and 5-fluorouracil drugs, having antiinflammatory property with distinctive hydrophilicity, were likewise delivered by utilizing the CS-GO complex with a pH-dependent release [66]. GO is modified as a carrier for delivering cancer drugs that are water soluble. The solubility in the physiological and aqueous solutions can be increased by the functionalised NGO with PEG [47].

\section{Biosensing and bioimaging}

Derivatives of graphene, including GO, artificially reduce GO (rGO) [66], and doped graphene [66] has been studied to know its universal implementations in biodetecting and biosensing for biomolecules such as thrombin [67], oligonucleotides [68], ATP [46], amino corrosives [69] and dopamine [70]. Nowadays, various biosensors-based GO have been produced, such as: (1) utilization of fluorescence quenching capacity of graphene which is supereffective and few FRET-based biosensors have been created [50, 67]; (2) FRET-based biosensors of graphene have been created on the basis of their electric property [71].

Self-assembling and controllable graphene biomolecules permit assembling ultrasensitive biosensors for recognition of DNA and different atoms [72, 73]. GO-based biosensors have been developed by taking advantage of their unique physiochemical properties such as extensive surface region, great electrical conducting ability and the magnificent ability for stacking different biomolecules by means of chemical or physical association [73-75].

Multilayered ultrathin graphene films, assembled by using layer-by-layer assembly technique, showed catalytic activity against reduced $\mathrm{H}_{2} \mathrm{O}_{2}$. Graphene-ultrathin films stimulate the production of advanced biosensing and electrochemical sensors [76].

\section{Cancer treatment}

Graphene is used to detect early stage of cancer cells [77]. With the tumour sphere assay, the functionality as well as the clonal expansion of the anchorage-independent single cancer stem cell can be measured [77]. GO restricts the formation of tumour sphere effectively in various cell lines that include ovarian, pancreatic, breast, lung cancers and glioblastoma. It is astonishing that GO is less toxic for cancer cells than normal fibroblastic cells. GO therapy inhibits Notch and Wnt driven signal pathways and STAT1/3 signalling, and antioxidant response depends on NRF2. It was reported that in cancer cells, GO induces the responses of toll-like receptors and can cause autophagy [78] and antitumour effects. CT26 colon cancer cells engulf the GO, and on the other hand trigger TLR-4 [79], TLR-9 signalling pathways and autophagy. GO when injected into mice (immunocompetent) having CT26 colon cancer cells [78] not only prevent the progression of tumour, but also induces autophagy [80], immune responses and cell death [81]. For effective hydrophobic medication (drugs) delivery, NGO is functionalized having six-arm polyethylene glycol and efficiently connected to tumour cell lines having therapeutic efficacy [37, 82] along with a high cell uptake. Conjugate PEG-GO exhibited malignancy in xenograft models and thus have high therapeutic value [83]. Presently, it has 
been considered that due to oxidative stress induction and depolarization of mitochondria, caspase activation bringing about necrotic and apoptotic cell death [84], the phototherapeutic impact of NGO subordinates occurs. For improvement of therapeutic adequacy, PEG-GO was utilized as a transporter for photothermal, DOX and chemical therapy [63]. Graphene/ $\mathrm{TiO}_{2}$ nano-hybrid composites additionally indicated high restorative ability which depends on the photocatalytic [33] and photothermal therapy. PEGylated GO utilizing xenograft tumour models of the mouse has shown higher uptake of PEG-modified GO by tumour cells, because of exceptionally productive tumour targeting of GO brought on by enhanced permeability and retention effect [83]. The nanosheet which is a hybrid mixture of GO and gold nanoparticles (AuNPs) easily adheres on the cell surface and promotes a type of cancer therapy by the mechanism of photothermal effect [85].

\section{Substrates for antibacterial effects}

Silver nanoparticle preparation and antibacterial effect on GO sheets have been reported [86]. GO has been geared up in the presence of sodium citrate and silver nitrate. Characterization of GO was done physicochemically by using thermogravimetric analysis (TGA), XRD, TEM, UV-Vis and Raman's spectroscopy. Using the standard counting plate methodology, the antibacterial property of GO and GO-Ag against microbes was observed. Dispersion of GO showed negligible antimicrobial activity against the microorganism and GO-Ag compound showed an increased antibacterial activity. The activity for antibiofilm was also observed on Pseudomonas aeruginosa, on a stainless steel surface showing $100 \%$ inhibition rate when exposed to the GO-Ag nanocomposite [87, 88]. Bao et al. [89] had a similar result using a disc diffusion test and evaluated the antibacterial property of GO by observing an inhibition zone surrounding the GO disc showing toxicity of bacteria against Staphylococcus aureus and Escherichia.coli. However, the GO-Ag compound resulted in P. aeruginosa inhibition [67]. The GO-Ag sample hinders $P$. aeruginosa growth [67]. The RGO and GO-based paper/sheet has the ability to inhibit both Gram-negative and Gram-positive bacterial growth [25]. Graphene derivatives show antibacterial impact because of layer disruption [90]. Since it is cost-effective, it opens a new door in clinical and ecological applications of GO [29]. If we compare with GO, Gt, rGO and GtO graphene subordinates, it has been found out that the antibacterial property diminishes in them as we move towards GtO.

$\mathrm{GO}$ and $\mathrm{rGO}$ show more prominent antibacterial activity than others $[38,91]$ by causing membrane stress. The stress is generated by the pointed uneven corner of graphene, which leads to cell membrane damage, ejaculation of RNA and membrane integrity loss [92]. When the concentration, incubation time and the conditions are same, GO shows the highest antibacterial activity as $\mathrm{rGO}, \mathrm{Gt}$ and then GtO. The antimicrobial mechanism of carbon nanotubes, such as (1) deposition of the cell on materials which are graphene based, (2) membrane stress when sharp nanosheets directly contact cells of the body and (3) oxidation, independent of superoxide anion, is suited for materials based on graphene. The bacterial activity of GtO is much stronger in comparison to GO [39]. Although graphene-based materials produce trace amount of ROS, the minor antibacterial activity of GtO is not negligible [86].

\section{Scaffolds for mammalian cell culture}

The CVD substrate of graphene is biologically compatible with human mesenchymal cells (hMSCs) and human osteoblasts. Cell lines grown in the presence of graphene show higher rate of proliferation, growth and differentiation [93] in comparison to the $\mathrm{SiO}$ substrate $[6,94,95]$. It has been reported that the use of different GO materials for cell cultures of lung epithelium have no impact on the viability and biological response of the cell [96-98]. NIH-3T3 fibroblasts behaviour was studied in different substrates covered with carbon nanomaterial, for example, GO, carbon nanotubes and RGO. The substrates coated with carbon nanomaterial had enhanced gene transfection efficiency and high biocompatibility [99]. Graphene/chitosan films demonstrated promising application to enhance and repair tissue functions in tissue engineering [100]. CVD-developed graphene substrate has also proved to be biocompatible for hMSCs and also for human osteoblasts with a higher rate of expansion of cell and stimulating the development and differentiation of cells [94]. Multilayered GO nanosheet assembled by layerby-layer technique can improve the mechanical properties of polyelectrolyte multilayer films for better attachment of cells [101].

\section{Differentiation of stem cells}

A noble platform of development for growth and differentiation of neuronal stem cell is an important norm for autologous tissue engineering and cell therapy to treat neurodegenerative diseases as well as neuronal disorders. Graphene is utilized for stem cells culture. Recently, human mesenchymal stem cell neuronal differentiation (hMSCs) was seen on the surface of graphene, as it supports a cell-adhesive coat bearing electrifying coupling impact for stimulation of stem cell differentiation [102]. Likewise, graphene additionally improved the differentiation of bones in comparison to regular growth factor [28]. Graphene provides an environment in which mesenchymal stem cells of a human (hMSCs) are organized in a 3D spheroids manner, essential to produce neurons from hMSCs. The monolayer of graphene regulates 
human mesenchymal stem cells (hMSCs) growth and development [103]. Substrates coated by GO increase embryonic stem (ES) cell differentiation in mouse into haematopoietic cells [104]. Graphene foam, a porous 3-D structure is being used in the energy conversion/storage system and electronics, areas of tissue engineering, to construct a scaffold of neural stem cell as it predominant to traditional inert biomaterials [105].

\section{Graphene in biomedical implantation}

In the last few decades, a lot of new therapies and devices based on materials have been discovered for the treatment of various diseases. New metallic alloys such as stainless steel and Nitinol (NiTi) have often been used in biomedical implants because of their advanced mechanistic properties [106]. Although there are major concerns regarding their use due to their exogenous cytotoxicity, these metallic alloys lack cellular adhesion. However, these may interact with proteins or other living cells leading to a strong immunological reaction that may affect the device functionality [106-108]. The unique properties of graphene along with its ability to form conjugates with other molecules due to the availability of a high number of functional groups gives an opportunity to create biocomposites with modified properties.

Graphene-based materials play vital roles in bone and tissue engineering. Regeneration of the bone tissues and their mineralization are the important factors in the process of reconstruction of bone defects [109]. One of the most commonly used strategies is the use of grafts, as spontaneous regeneration is not always feasible. Due to the high cost of grafting [110] and some of the disadvantages like lack of viable cells, the risk of immunogenicity and infection transmission, synthetic bone substitutes based on ceramic [111] are used in clinical practice [112]. Graphene and its derivatives, when combined with ceramics, give rise to materials having enhanced mechanical as well as osteogenic properties. HAp, a commonly used material, has been combined with graphene for enhanced capabilities [113, 114]. The addition of chitosan or PEG to HAp/GO nanocomposite can release the considerably high amount of calcium and phosphorus ions as compared to only HAp $[114,115]$. Several improvements have been observed in the mechanical and physical properties when graphene is combined with HAp. The addition of GO to the coating of HAp increases the strength [116]. Moreover, the coating with modified GO offered resistance to corrosion and it was also possible to increase the elastic module of HAp and fracture toughness $[117,118]$. Incorporation of GO nanoflakes in the scaffolds of gelatin and HAp produced compressive strengths and the yield was also increased compared to gelatin/HAp [119].

Graphene improves the functionality of HAp. Certain glass-ceramic reactive materials also have the ability to bind to bones and they are biodegradable as well [120]. Addition of $0.5 \mathrm{wt} \%$ of graphene into $58 \mathrm{~S}$ bioglass via laser sintering increases the fracture toughness and strength [121]. Notably, the properties of HAp and bioglass can be influenced by rGO which depends on the concentration. The improvements of mechanical properties of the bioceramic materials by graphene and other related materials are done by bridging, sheet pullout and three-dimensional crack deflection mechanisms $[118,122,123]$. The graphene has a surface area for contact. Thus, graphene-modified bioceramics often have enhanced bioactivity. In a culture of mesenchymal cells (MSC) dispersed in a colloidal solution of HAp coated with rGO, elevated alkaline phosphates activity (ALP) and deposition of nodules of calcium than HAp or rGO alone were shown. Moreover, the cells also showed a high expression level of osteopontin and osteocalcin that play important roles in bone mineralization [124]. As osteocalcin is expressed in late stages of differentiation of osteoblasts [125], it is likely that the rGO/HAp composite promotes differentiation of these cells [124]. Other osteoconductive bioceramics like calcium phosphate as well as $\beta$-tricalcium phosphate ( $\beta$-TCP) can be mixed with graphene to improve its in vitro bioactivity. In in vitro studies, $\mathrm{GO} / \beta$-TCP composite elevated the activity of ALP and also the osteogenic related gene expression in MSCs of bone marrow. GO-modified scaffolds also increase the expression level of Wnt cell signalling pathway proteins, suggesting the role of this pathway in the differentiation of osteoblasts [126]. Graphene-mediated enhancements in the differentiation of osteoblasts is also seen in vivo. Calvarial defects of critical sizes were produced in rabbits and then cured with GO/ $\beta$-TCP scaffold, which resulted in higher rate of naive bone formation than defects filled by unchanged $\beta$-TCP alone [126]. Similar observations were also found in the case of rGO/HAp graft which showed considerably higher (52\%) bone density than HAp (26\%) as well as untreated control (17\%) [127].

Polymeric substances have wide use in dentistry and biomedical field [128]. However, some of the polymer-based materials used in regenerative and reconstructive dentistry are poorly suited for areas that bear the load and may induce inflammatory responses. Moreover, the degradation of these materials may cause induction of an autocatalytic ester breakdown that lowers the $\mathrm{pH}$, which is not suitable for cell viability $[129,130]$. These limitations can be overcome by blending the polymers with graphene and its derivatives for the production of composites with improved capabilities. Graphene is a potential candidate for coating of the implants. Nnitinol coated with graphene (Gr-NiTi) supports the excellent growth of endothelial cells and smooth muscle with better cell proliferation and no significant cytotoxic properties [131].

Graphene-based materials are used extensively in dental implants [132]. A crucial aspect of dental implants is the 
appropriate measure of the prevention of mechanical failure after implantation. Studies have found that silicatized titanium plates have higher bond strength and good adhesion with a carbon-graphite fibre-reinforced polymer [133]. An important challenge with the dental implants is the formation of biofilms and aggregation of microbial agents on the surface of the implant. To overcome this, researchers have tried various coating materials with antibacterial properties. A coating of artificial acrylic teeth surface with graphene and zinc oxide nanocomposite decreases the deposition of cariogenic Streptococcus mutans bacteria and biofilm formation [23]. PCL/graphene was the material preferred for the production of porous scaffolds [134]. One of the concerns is how to improve the osseointegration of a dental implant. Numerous efforts have been made to enhance the osseointegration property by promoting the attachment, differentiation and proliferation of bone-forming cells on the implant surface [132].

\section{Photothermal therapy}

A phototherapy is a useful approach that can treat a variety of diseases. In addition to gene therapy and chemotherapy, phototherapy also has the ability to control the progression of disease by irradiation of specific light that includes photothermal as well as photodynamic therapy (PTT, PDT). In PTT, a light-absorbing agent is used that generates heat when irradiated by light [135]. Exposure of biological tissues to such temperature results in destruction of the abnormal cells [136]. Based upon this in the field of phototherapy, they can absorb light strongly near the infrared region and have a large surface area with a high number of functional groups [137]. Liu et al. first reported the combined use of GO with PTT in successful tumour suppression [83]. DOXloaded PEGylated NGO can deliver the drug to the tumourigenic region along with the heat that is generated to facilitate combined chemotherapy and photothermal treatment [138]. This approach is more useful than chemotherapy or photothermal treatment alone. Hu et al. developed rGO-tagged quantum dot (QD-CRGO) nanocomposite, which combines PTT therapy with fluorescence bioimaging of the cell/ tumour. GO functionalized with biocompatible porphyrin was used as a platform for PTT of brain cancer. This PGO was found to be more stable than $\mathrm{rGO}$ and more, importantly, PGO caused depletion of a high number of brain cancer cells in vitro [139]. However, PTT alone cannot be used as such to destroy tumour cells as the heat is heterogeneously distributed in these cells [140]. PTT is used in combination with other strategies which may involve the modification of GO properties to enhance the therapeutic efficiency.

In PDT, a photosensitizer (PS) is irradiated with suitable light to generate free radicals and/or ROS that irreversibly damages the cancer cells [141]. Hypocrellin-A (HA, a hydrophobic perylenequinonoid anticancer drug having photodynamic properties) was immobilized on GO with the help of $\pi-\pi$ interaction, hydrogen bonding and hydrophobic interaction [142]. The excitement of GO-HA at a particular wavelength of light generates singlet oxygen. High cellular uptake of GO-HA was revealed using HeLa cells and significant cell death by irradiation of light was also evident from the studies. Tian et al. showed the benefits of photothermal therapy with photodynamic treatment [86]. Chlorine6 (Ce6, a photosensitizer molecule) was loaded on PEGylated GO and the composite was delivered to KB cells (HeLa derivative cells). It was found that the delivery of Ce 6 was promoted by a low power density laser $(808 \mathrm{~nm})$ by mild local heating due to the graphene, which has a photothermal effect. PDT is still a challenge, as the frequently used photosensitizers are hydrophobic.

\section{Graphene in mass spectrometry}

The properties of graphene, like large surface area, high thermal conductivity stability and the ability to interact with a variety of small molecules, allow it to be used widely in analytical chemistry based on mass spectrometry [143]. Derivatives of graphene are considered as useful matrices that can be replaced with organic matrices that are used conventionally for laser desorption-ionization mass spectrometry (LDI-MS), as they are very efficient in absorbing and transferring energy to the analytes [15]. The efficacy of graphene is much higher than that of $\mathrm{GO}$ and $\mathrm{rGO}$, because of its electron transfer and high heat dissipation properties [144]. The hydrophobic properties of graphene make the affinity probe of LDI-MS more suitable for analysis of trace amounts of analytes having an aromatic structure which includes proteins [144], ssDNA, small molecules [69] and pollutants [145]. The unique properties of graphene make it an excellent absorbent in solid-phase extraction.

Graphene can be used as a good detection platform for ssDNA was first proposed by Tang et al. [144]. They found that with the help of graphene, very low limits of detection can be achieved for DNA as well as protein samples. Dong et al. found that the MALDI-MS of low molecular weight substances uses graphene as a matrix [69]. Detection of both polar compounds such as amino acids nucleosides and others as well as non-polar compounds such as steroids can be possible. The new matrix has the potential to eliminate the interference of matrix background ions, avoid the fragmentation of analytes and also improve shot-to-shot reproducibility. Later, Lu et al. introduced the use of graphene flakes as a very effective matrix for analysis of large-scale small molecules, which include peptides and fatty acids [146]. According to this study, graphene can be used to characterize polymers with average molecular weights from 425 to $3500 \mathrm{kDa}$. Graphene matrix can minimize the reduction of some redox-sensitive 
molecules such as methylene blue and riboflavin in MALDI [147]. Compared with conventional organic matrixes and other nano-sized inorganic matrixes, graphene matrixes show some important advantages, which include interference-free low molecular mass region, reduced spot-to-spot difference, high salt tolerance, great ability in negative ion mode and minimization of the reduction of redox-sensitive molecules [143].

Conjugation of the aptamer to GO makes it suitable to be used as specific affinity probe [91]. GO can also be used as a supporting matrix for the synthesis of $\mathrm{Fe}_{3} \mathrm{O}_{4}$ nanocomposites for increased separation of sulphonamide antibiotics with magnetic retrieval of graphene [148]. $\mathrm{TiO}_{2}$-conjugated GO nanocomposites enhance the binding of phosphorylated biomolecules [149]. Moreover, GO-based monohybrid films were synthesized to increase the efficiency of LDI by immobilizing GO on a solid surface and then multiwalled carbon nanotubes(MWCNT) and gold nanostructure were incorporated subsequently $[150,151]$. The GO-MWCNT composite showed high potential for analysis of phospholipase activity by LDI-MS [152] along with other small molecules and tissue imaging [153]. The efficiency of LDI-MS using GO-MWCNT platform can be increased further by increasing the thickness and roughness of the surface [154].

A functional graphene paper was made using a pulsed laser engineering approach by spreading graphitic nano-spheres homogenously and used for matrix-free mass spectrometry. This technique increases the stability of the graphene paper as well as its hydrophobicity and electric conductivity. It also increases the imaging of trace element of small molecules and the detection limit is also increased twofold compared to other commercial products [155]. As a very elemental form of graphene, 2D graphene has high compatibility and duration needed for many imaging mass spectrometry (IMS) experiments.

Graphene has a great potential as an adsorbent in solidphase extraction due to its properties, where it can play the dual role of an extractor and matrix in a MALDI-based MS analysis [143]. After the absorption and enrichment of the analyte from a complex sample mixture, it is very important to separate graphene from the mixture. With the help of centrifugation, graphene pellets can be collected after removing the supernatant [144]. Sometimes, it is necessary to wash the graphene after separation, which is done by water or some other solvents $[156,157]$. To minimize the loss of graphene, magnetic graphene can be prepared by combining $\mathrm{Fe}_{3} \mathrm{O}_{4}$ or cobalt particles with graphene sheets $[91,156,158]$.

\section{Future uses of graphene}

The nanomaterial based on graphene has been widely used in nonmedical fields since the last decade. Recently from a number of publications, we have evidence that graphene is attracting the attention of biomedical scientists. The wide range of applications in the delivery of gene/drug has exploited various properties of graphene such as $\pi-\pi$ stacking and the loading of small molecular drugs on two-dimensional plane surface by hydrophobic interactions. The utilization of free $\pi$ electrons, which disclose a negative charge on the surface, has been used to precipitate proteins and genes. GO surfaces enable possibilities for covalently linked and chemically assorted small molecules and similar proteins [105]. Although the research on graphene and its derivatives is at its early stage, in the upcoming days it will provide wide applications for biomaterial science and regenerative medicines $[95,159$, 160]. Besides its wide application, the toxic effect of graphene has been recently reported from various studies. The future approach may be to nullify the toxic effect without affecting the physical and chemical properties [161].

\section{Conclusion}

Graphene and graphene-based composite have exclusive electronic, biological, mechanical, as well as unique optical properties. Researchers nowadays have developed various transistors based on graphene molecules, for use in the biomedical field such as biosensing via fluorescence, cell growth and its differentiation for the treatment of many diseases. The formation of a unique biosensor based on graphene has strong functionalization under various physiological conditions with a loss in few properties. As an emerging field, research on nanomaterial scaffolds of graphene for the implementation of stem cell culture deserves notable attention. To build therapeutics on the basis of graphene, researchers might standardize its derivatives as well as check functionalization of this on the biological field to know the response of cells to many graphene derivatives. Graphene may come up as a unique nanoparticle to be used in the biomedical study by efficient association with various branches of science.

Acknowledgements SP and SM are thankful to MHRD for financial support. SB is thankful to Odisha DBT for financial support. This work is supported by DBT-Government of India to MM via grants no BT/ PR21857/NNT/28/1238/2017.

Open Access This article is distributed under the terms of the Creative Commons Attribution 4.0 International License (http://creativeco mmons.org/licenses/by/4.0/), which permits unrestricted use, distribution, and reproduction in any medium, provided you give appropriate credit to the original author(s) and the source, provide a link to the Creative Commons license, and indicate if changes were made.

\section{References}

1. Chen, J.H., Jang, C., Xiao, S., Ishigami, M., Fuhrer, M.S.: Intrinsic and extrinsic performance limits of graphene devices on $\mathrm{SiO}_{2}$. Nat. Nanotechnol. 3(4), 206 (2008) 
2. Choi, W., Lahiri, I., Seelaboyina, R., Kang, Y.S.: Synthesis of graphene and its applications: a review. Crit. Rev. Solid State Mater. Sci. 35(1), 52-71 (2010)

3. Geim, A.K., Novoselov, K.S.: The rise of graphene. Nat. Mater. 6(3), 183 (2007)

4. Allen, M.J., Tung, V.C., Kaner, R.B.: Honeycomb carbon: a review of graphene. Chem. Rev. 110(1), 132-145 (2009)

5. Compton, O.C., Nguyen, S.T.: Graphene oxide, highly reduced graphene oxide, and graphene: versatile building blocks for carbon-based materials. Small 6(6), 711-723 (2010)

6. Acik, M., Mattevi, C., Gong, C., Lee, G., Cho, K., Chhowalla, M., Chabal, Y.J.: The role of intercalated water in multilayered graphene oxide. ACS Nano 4(10), 5861-5868 (2010)

7. Sanchez, V.C., Jachak, A., Hurt, R.H., Kane, A.B.: Biological interactions of graphene-family nanomaterials: an interdisciplinary review. Chem. Res. Toxicol. 25(1), 15-34 (2011)

8. Edwards, R.S., Coleman, K.S.: Graphene synthesis: relationship to applications. Nanoscale. 5(1), 38-51 (2013)

9. Warner, J.H., Schaffel, F., Rummeli, M., Bachmatiuk, A.: Graphene: fundamentals and emergent applications. Newnes (2012)

10. Novoselov, K.S., Geim, A.K., Morozov, S.V., Jiang, D., Zhang, Y., Dubonos, S.V., Grigorieva, I.V., Firsov, A.A.: Electric field effect in atomically thin carbon films. Science 306(5696), 666669 (2004)

11. Reina, A., Jia, X., Ho, J., Nezich, D., Son, H., Bulovic, V., Dresselhaus, M.S., Kong, J.: Large area, few-layer graphene films on arbitrary substrates by chemical vapor deposition. Nano Lett. 9(1), 30-35 (2008)

12. Dato, A., Radmilovic, V., Lee, Z., Phillips, J., Frenklach, M.: Substrate-free gas-phase synthesis of graphene sheets. Nano Lett. 8(7), 2012-2016 (2008)

13. Verdejo, R., Bernal, M.M., Romasanta, L.J., Lopez-Manchado, M.A.: Graphene filled polymer nanocomposites. J. Mater. Chem. 21(10), 3301-3310 (2011)

14. Park, S., Ruoff, R.S.: Chemical methods for the production of graphenes. Nat. Nanotechnol. 4(4), 217-224 (2009)

15. Chung, C., Kim, Y.-K., Shin, D., Ryoo, S.-R., Hong, B.H., Min, D.-H.: Biomedical applications of graphene and graphene oxide. Acc. Chem. Res. 46(10), 2211-2224 (2013)

16. Loh, K.P., Bao, Q., Eda, G., Chhowalla, M.: Graphene oxide as a chemically tunable platform for optical applications. Nat. Chem. 2(12), 1015 (2010)

17. Gao, W.: The Chemistry of Graphene Oxide in Graphene Oxide, pp. 61-95. Springer, Berlin (2015)

18. Li, B., Cao, X., Ong, H.G., Cheah, J.W., Zhou, X., Yin, Z., Li, H., Wang, J., Boey, F., Huang, W.: All-carbon electronic devices fabricated by directly grown single-walled carbon nanotubes on reduced graphene oxide electrodes. Adv. Mater. 22(28), 30583061 (2010)

19. Liu, Z., Robinson, J.T., Tabakman, S.M., Yang, K., Dai, H.: Carbon materials for drug delivery and cancer therapy. Mater. Today 14(7-8), 316-323 (2011)

20. Jiang, Z., Zhang, Y., Stormer, H., Kim, P.: Quantum Hall states near the charge-neutral Dirac point in graphene. Phys. Rev. Lett. 99(10), 106802 (2007)

21. Rao, C.E.N.E.R., Sood, A.E.K., Subrahmanyam, K.E.S., Govindaraj, A.: Graphene: the new two-dimensional nanomaterial. Angew. Chem. Int. Ed. 48(42), 7752-7777 (2009)

22. Marcano, D.C., Kosynkin, D.V., Berlin, J.M., Sinitskii, A., Sun, Z., Slesarev, A., Alemany, L.B., Lu, W., Tour, J.M.: Improved synthesis of graphene oxide. ACS Nano 4(8), 4806-4814 (2010)

23. Kulshrestha, S., Khan, S., Meena, R., Singh, B.R., Khan, A.U.: A graphene/zinc oxide nanocomposite film protects dental implant surfaces against cariogenic Streptococcus mutans. Biofouling 30(10), 1281-1294 (2014)
24. Goenka, S., Sant, V., Sant, S.: Graphene-based nanomaterials for drug delivery and tissue engineering. J. Control. Release 173, 75-88 (2014)

25. Wang, Y., Li, Z., Wang, J., Li, J., Lin, Y.: Graphene and graphene oxide: biofunctionalization and applications in biotechnology. Trends Biotechnol. 29(5), 205-212 (2011)

26. Kuila, T., Bose, S., Khanra, P., Mishra, A.K., Kim, N.H., Lee, J.H.: Recent advances in graphene-based biosensors. Biosens. Bioelectron. 26(12), 4637-4648 (2011)

27. Shen, J., Zhu, Y., Yang, X., Li, C.: Graphene quantum dots: emergent nanolights for bioimaging, sensors, catalysis and photovoltaic devices. Chem. Commun. 48(31), 3686-3699 (2012)

28. Nayak, T.R., Andersen, H., Makam, V.S., Khaw, C., Bae, S., Xu, X., Ee, P.-L.R., Ahn, J.-H., Hong, B.H., Pastorin, G.: Graphene for controlled and accelerated osteogenic differentiation of human mesenchymal stem cells. ACS Nano 5(6), 4670-4678 (2011)

29. Crowder, S.W., Prasai, D., Rath, R., Balikov, D.A., Bae, H., Bolotin, K.I., Sung, H.-J.: Three-dimensional graphene foams promote osteogenic differentiation of human mesenchymal stem cells. Nanoscale. 5(10), 4171-4176 (2013)

30. Lee, W.C., Lim, C.H.Y., Shi, H., Tang, L.A., Wang, Y., Lim, C.T., Loh, K.P.: Origin of enhanced stem cell growth and differentiation on graphene and graphene oxide. ACS Nano 5(9), 7334-7341 (2011)

31. Yoon, H.H., Bhang, S.H., Kim, T., Yu, T., Hyeon, T., Kim, B.S.: Dual roles of graphene oxide in chondrogenic differentiation of adult stem cells: cell-adhesion substrate and growth factor-delivery carrier. Adv. Func. Mater. 24(41), 6455-6464 (2014)

32. Kim, J., Choi, K.S., Kim, Y., Lim, K.T., Seonwoo, H., Park, Y., Kim, D.H., Choung, P.H., Cho, C.S., Kim, S.Y.: Bioactive effects of graphene oxide cell culture substratum on structure and function of human adipose-derived stem cells. J. Biomed. Mater. Res. Part A 101(12), 3520-3530 (2013)

33. Lee, T.-J., Park, S., Bhang, S.H., Yoon, J.-K., Jo, I., Jeong, G.-J., Hong, B.H., Kim, B.-S.: Graphene enhances the cardiomyogenic differentiation of human embryonic stem cells. Biochem. Biophys. Res. Commun. 452(1), 174-180 (2014)

34. Park, J., Park, S., Ryu, S., Bhang, S.H., Kim, J., Yoon, J.K., Park, Y.H., Cho, S.P., Lee, S., Hong, B.H.: Graphene-regulated cardiomyogenic differentiation process of mesenchymal stem cells by enhancing the expression of extracellular matrix proteins and cell signaling molecules. Adv. Healthc. Mater. 3(2), 176-181 (2014)

35. Li, N., Zhang, Q., Gao, S., Song, Q., Huang, R., Wang, L., Liu, L., Dai, J., Tang, M., Cheng, G.: Three-dimensional graphene foam as a biocompatible and conductive scaffold for neural stem cells. Sci. Rep. 3, 1604 (2013)

36. Ghuge, A.D., Shirode, A.R., Kadam, V.J.: Graphene: a comprehensive review. Curr. Drug Targets. 18(6), 724-733 (2017)

37. Sun, X., Liu, Z., Welsher, K., Robinson, J.T., Goodwin, A., Zaric, S., Dai, H.: Nano-graphene oxide for cellular imaging and drug delivery. Nano Res. 1(3), 203-212 (2008)

38. Akhavan, O., Ghaderi, E.: Toxicity of graphene and graphene oxide nanowalls against bacteria. ACS Nano 4(10), 5731-5736 (2010)

39. Perreault, F., De Faria, A.F., Nejati, S., Elimelech, M.: Antimicrobial properties of graphene oxide nanosheets: why size matters. ACS Nano 9(7), 7226-7236 (2015)

40. Lu, C.H., Yang, H.H., Zhu, C.L., Chen, X., Chen, G.N.: A graphene platform for sensing biomolecules. Angew. Chem. 121(26), 4879-4881 (2009)

41. Wang, L., Lee, K., Sun, Y.-Y., Lucking, M., Chen, Z., Zhao, J.J., Zhang, S.B.: Graphene oxide as an ideal substrate for hydrogen storage. ACS Nano 3(10), 2995-3000 (2009) 
42. Song, Y., Qu, K., Zhao, C., Ren, J., Qu, X.: Graphene oxide: intrinsic peroxidase catalytic activity and its application to glucose detection. Adv. Mater. 22(19), 2206-2210 (2010)

43. Zhang, J., Zhang, F., Yang, H., Huang, X., Liu, H., Zhang, J., Guo, S.: Graphene oxide as a matrix for enzyme immobilization. Langmuir 26(9), 6083-6085 (2010)

44. Zhang, J., Sun, Y., Xu, B., Zhang, H., Gao, Y., Zhang, H., Song, D.: A novel surface plasmon resonance biosensor based on graphene oxide decorated with gold nanorod-antibody conjugates for determination of transferrin. Biosens. Bioelectron. 45, 230236 (2013)

45. Dong, H., Gao, W., Yan, F., Ji, H., Ju, H.: Fluorescence resonance energy transfer between quantum dots and graphene oxide for sensing biomolecules. Anal. Chem. 82(13), 5511-5517 (2010)

46. Shao, Y., Wang, J., Wu, H., Liu, J., Aksay, I.A., Lin, Y.: Graphene based electrochemical sensors and biosensors: a review. Electroanalysis 22(10), 1027-1036 (2010)

47. Zhang, M., Yin, B.-C., Wang, X.-F., Ye, B.-C.: Interaction of peptides with graphene oxide and its application for real-time monitoring of protease activity. Chem. Commun. 47(8), 23992401 (2011)

48. Takahashi, H., Li, B., Sasaki, T., Miyazaki, C., Kajino, T., Inagaki, S.: Catalytic activity in organic solvents and stability of immobilized enzymes depend on the pore size and surface characteristics of mesoporous silica. Chem. Mater. 12(11), 33013305 (2000)

49. Chen, J., Leng, J., Yang, X., Liao, L., Liu, L., Xiao, A.: Enhanced performance of magnetic graphene oxide-immobilized laccase and its application for the decolorization of dyes. Molecules 22(2), 221 (2017)

50. Gong, A., Zhu, C.-T., Xu, Y., Wang, F.-Q., Wu, F.-A., Wang, J.: Moving and unsinkable graphene sheets immobilized enzyme for microfluidic biocatalysis. Sci. Rep. 7(1), 4309 (2017)

51. Srivastava, G., Singh, K., Talat, M., Srivastava, O.N., Kayastha, A.M.: Functionalized graphene sheets as immobilization matrix for fenugreek $\beta$-amylase: enzyme kinetics and stability studies. PLoS One 9(11), e113408 (2014)

52. Grigorenko, B.L., Krylov, A.I., Nemukhin, A.V.: Molecular modeling clarifies the mechanism of chromophore maturation in the green fluorescent protein. J. Am. Chem. Soc. 139(30), 10239-10249 (2017)

53. Rafat, M., Cléroux, C.A., Fong, W.G., Baker, A.N., Leonard, B.C., O'Connor, M.D., Tsilfidis, C.: PEG-PLA microparticles for encapsulation and delivery of Tat-EGFP to retinal cells. Biomaterials 31(12), 3414-3421 (2010)

54. Bindels, D.S., Haarbosch, L., Van Weeren, L., Postma, M., Wiese, K.E., Mastop, M., Aumonier, S., Gotthard, G., Royant, A., Hink, M.A.: mScarlet: a bright monomeric red fluorescent protein for cellular imaging. Nat. Methods 14(1), 53 (2017)

55. Tschopp, P., Duboule, D.: The Genetics of Murine Hox Loci: TAMERE, STRING, and PANTHERE to Engineer Chromosome Variants, in Hox Genes, pp. 89-102. Springer, Berlin (2014)

56. Hong, S.W., Lee, J.H., Kang, S.H., Hwang, E.Y., Hwang, Y.-S., Lee, M.H., Han, D.-W., Park, J.-C: Enhanced neural cell adhesion and neurite outgrowth on graphene-based biomimetic substrates. BioMed Res. Int. 2014 (2014)

57. Gurunathan, S., Han, J.W., Kim, E., Kwon, D.-N., Park, J.-K., Kim, J.-H.: Enhanced green fluorescent protein-mediated synthesis of biocompatible graphene. J. Nanobiotechnol. 12(1), 41 (2014)

58. Feng, L., Zhang, S., Liu, Z.: Graphene based gene transfection. Nanoscale. 3(3), 1252-1257 (2011)

59. Rana, V.K., Choi, M.C., Kong, J.Y., Kim, G.Y., Kim, M.J., Kim, S.H., Mishra, S., Singh, R.P., Ha, C.S.: Synthesis and drug-delivery behavior of chitosan-functionalized graphene oxide hybrid nanosheets. Macromol. Mater. Eng. 296(2), 131-140 (2011)
60. Bao, H., Pan, Y., Ping, Y., Sahoo, N.G., Wu, T., Li, L., Li, J., Gan, L.H.: Chitosan-functionalized graphene oxide as a nanocarrier for drug and gene delivery. Small 7(11), 1569-1578 (2011)

61. Jaeger, M., Schubert, S., Ochrimenko, S., Fischer, D., Schubert, U.S.: Branched and linear poly (ethylene imine)-based conjugates: synthetic modification, characterization, and application. Chem. Soc. Rev. 41(13), 4755-4767 (2012)

62. Kim, H., Kim, W.J.: Photothermally controlled gene delivery by reduced graphene oxide-polyethylenimine nanocomposite. Small 10(1), 117-126 (2014)

63. Chen, B., Liu, M., Zhang, L., Huang, J., Yao, J., Zhang, Z.: Polyethylenimine-functionalized graphene oxide as an efficient gene delivery vector. J. Mater. Chem. 21(21), 7736-7741 (2011)

64. Pan, Y., Bao, H., Sahoo, N.G., Wu, T., Li, L.: Water-soluble poly ( $N$-isopropylacrylamide)-graphene sheets synthesized via click chemistry for drug delivery. Adv. Func. Mater. 21(14), 2754-2763 (2011)

65. Yang, X., Zhang, X., Liu, Z., Ma, Y., Huang, Y., Chen, Y.: High-efficiency loading and controlled release of doxorubicin hydrochloride on graphene oxide. J. Phys. Chem. C. 112(45), 17554-17558 (2008)

66. Tang, L., Wang, Y., Li, Y., Feng, H., Lu, J., Li, J.: Preparation, structure, and electrochemical properties of reduced graphene sheet films. Adv. Func. Mater. 19(17), 2782-2789 (2009)

67. Chang, H., Tang, L., Wang, Y., Jiang, J., Li, J.: Graphene fluorescence resonance energy transfer aptasensor for the thrombin detection. Anal. Chem. 82(6), 2341-2346 (2010)

68. Tang, L., Wang, Y., Liu, Y., Li, J.: DNA-directed self-assembly of graphene oxide with applications to ultrasensitive oligonucleotide assay. ACS Nano 5(5), 3817-3822 (2011)

69. Dong, X., Cheng, J., Li, J., Wang, Y.: Graphene as a novel matrix for the analysis of small molecules by MALDI-TOF MS. Anal. Chem. 82(14), 6208-6214 (2010)

70. Wang, Y., Li, Y., Tang, L., Lu, J., Li, J.: Application of graphenemodified electrode for selective detection of dopamine. Electrochem. Commun. 11(4), 889-892 (2009)

71. Chen, H., Clarkson, B.H., Sun, K., Mansfield, J.F.: Self-assembly of synthetic hydroxyapatite nanorods into an enamel prism-like structure. J. Colloid Interface Sci. 288(1), 97-103 (2005)

72. Zeng, Q., Cheng, J., Tang, L., Liu, X., Liu, Y., Li, J., Jiang, J.: Self-assembled graphene-enzyme hierarchical nanostructures for electrochemical biosensing. Adv. Func. Mater. 20(19), 33663372 (2010)

73. Shen, H., Zhang, L., Liu, M., Zhang, Z.: Biomedical applications of graphene. Theranostics. 2(3), 283 (2012)

74. Wan, Y., Wang, Y., Wu, J., Zhang, D.: Graphene oxide sheetmediated silver enhancement for application to electrochemical biosensors. Anal. Chem. 83(3), 648-653 (2010)

75. Khalil, I., Rahmati, S., Julkapli, N.M., Yehye, W.A.: Graphene metal nanocomposites-Recent progress in electrochemical biosensing applications. J. Ind. Eng. Chem. 59, 425-439 (2017)

76. Ma, J., Cai, P., Qi, W., Kong, D., Wang, H.: The layer-by-layer assembly of polyelectrolyte functionalized graphene sheets: a potential tool for biosensing. Colloids Surf. A 426, 6-11 (2013)

77. Fiorillo, M., Verre, A.F., Iliut, M., Peiris-Pagés, M., Ozsvari, B., Gandara, R., Cappello, A.R., Sotgia, F., Vijayaraghavan, A., Lisanti, M.P.: Graphene oxide selectively targets cancer stem cells, across multiple tumor types: implications for non-toxic cancer treatment, via "differentiation-based nano-therapy". Oncotarget. 6(6), 3553 (2015)

78. Michaud, M., Martins, I., Sukkurwala, A.Q., Adjemian, S., Ma, Y., Pellegatti, P., Shen, S., Kepp, O., Scoazec, M., Mignot, G.: Autophagy-dependent anticancer immune responses induced by chemotherapeutic agents in mice. Science 334(6062), 1573-1577 (2011) 
79. Xu, Y., Jagannath, C., Liu, X.-D., Sharafkhaneh, A., Kolodziejska, K.E., Eissa, N.T.: Toll-like receptor 4 is a sensor for autophagy associated with innate immunity. Immunity $27(1)$, 135-144 (2007)

80. Levine, B.: Eating oneself and uninvited guests: autophagyrelated pathways in cellular defense. Cell 120(2), 159-162 (2005)

81. Chen, G.Y., Chen, C.L., Tuan, H.Y., Yuan, P.X., Li, K.C., Yang, H.J., Hu, Y.C.: Graphene oxide triggers toll-like receptors/ autophagy responses in vitro and inhibits tumor growth in vivo. Adv. Healthc. Mater. 3(9), 1486-1495 (2014)

82. Liu, Z., Robinson, J.T., Sun, X., Dai, H.: PEGylated nanographene oxide for delivery of water-insoluble cancer drugs. J. Am. Chem. Soc. 130(33), 10876-10877 (2008)

83. Yang, K., Zhang, S., Zhang, G., Sun, X., Lee, S.-T., Liu, Z.: Graphene in mice: ultrahigh in vivo tumor uptake and efficient photothermal therapy. Nano Lett. 10(9), 3318-3323 (2010)

84. Markovic, Z.M., Harhaji-Trajkovic, L.M., Todorovic-Markovic, B.M., Kepić, D.P., Arsikin, K.M., Jovanović, S.P., Pantovic, A.C., Dramićanin, M.D., Trajkovic, V.S.: In vitro comparison of the photothermal anticancer activity of graphene nanoparticles and carbon nanotubes. Biomaterials 32(4), 1121-1129 (2011)

85. Kang, S., Lee, J., Ryu, S., Kwon, Y., Kim, K.-H., Jeong, D.H., Paik, S.R., Kim, B.-S.: Gold nanoparticle/graphene oxide hybrid sheets attached on mesenchymal stem cells for effective photothermal cancer therapy. Chem. Mater. 29(8), 3461-3476 (2017)

86. Tian, B., Wang, C., Zhang, S., Feng, L., Liu, Z.: Photothermally enhanced photodynamic therapy delivered by nano-graphene oxide. ACS Nano 5(9), 7000-7009 (2011)

87. de Faria, A.F., Martinez, D.S.T., Meira, S.M.M., de Moraes, A.C.M., Brandelli, A., Souza Filho, A.G., Alves, O.L.: Antiadhesion and antibacterial activity of silver nanoparticles supported on graphene oxide sheets. Colloids Surf. B 113, 115-124 (2014)

88. Das, M.R., Sarma, R.K., Saikia, R., Kale, V.S., Shelke, M.V., Sengupta, P.: Synthesis of silver nanoparticles in an aqueous suspension of graphene oxide sheets and its antimicrobial activity. Colloids Surf. B 83(z), 16-22 (2011)

89. Bao, Q., Zhang, D., Qi, P.: Synthesis and characterization of silver nanoparticle and graphene oxide nanosheet composites as a bactericidal agent for water disinfection. J. Colloid Interface Sci. 360(2), 463-470 (2011)

90. Huang, H., Bai, W., Dong, C., Guo, R., Liu, Z.: An ultrasensitive electrochemical DNA biosensor based on graphene/Au nanorod/ polythionine for human papillomavirus DNA detection. Biosens. Bioelectron. 68, 442-446 (2015)

91. Gulbakan, B., Yasun, E., Shukoor, M.I., Zhu, Z., You, M., Tan, X., Sanchez, H., Powell, D.H., Dai, H., Tan, W.: A dual platform for selective analyte enrichment and ionization in mass spectrometry using aptamer-conjugated graphene oxide. J. Am. Chem. Soc. 132(49), 17408-17410 (2010)

92. Geim, A.K.: Graphene: status and prospects. Science 324(5934), 1530-1534 (2009)

93. Hu, X.-B., Liu, Y.-L., Wang, W.-J., Zhang, H.-W., Qin, Y., Guo, S., Zhang, X.-W., Fu, L., Huang, W.-H.: Biomimetic graphenebased 3D scaffold for long-term cell culture and real-time electrochemical monitoring. Anal. Chem. 90(2), 1136-1141 (2018)

94. Kalbacova, M., Broz, A., Kong, J., Kalbac, M.: Graphene substrates promote adherence of human osteoblasts and mesenchymal stromal cells. Carbon 48(15), 4323-4329 (2010)

95. Lee, W.C., Loh, K.P., Lim, C.T.: When stem cells meet graphene: opportunities and challenges in regenerative medicine. Biomaterials 155, 236-250 (2018)

96. Jasim, D.A., Lozano, N., Kostarelos, K.: Synthesis of few-layered, high-purity graphene oxide sheets from different graphite sources for biology. 2D Materials. 3(1), 014006 (2016)
97. Sasidharan, A., Panchakarla, L., Chandran, P., Menon, D., Nair, S., Rao, C., Koyakutty, M.: Differential nano-bio interactions and toxicity effects of pristine versus functionalized graphene. Nanoscale. 3(6), 2461-2464 (2011)

98. Li, Y., Yuan, H., von dem Bussche, A., Creighton, M., Hurt, R.H., Kane, A.B., Gao, H.: Graphene microsheets enter cells through spontaneous membrane penetration at edge asperities and corner sites. Proc. Natl. Acad. Sci. 110(30), 12295-12300 (2013)

99. Ryoo, S.-R., Kim, Y.-K., Kim, M.-H., Min, D.-H.: Behaviors of NIH-3T3 fibroblasts on graphene/carbon nanotubes: proliferation, focal adhesion, and gene transfection studies. ACS Nano 4(11), 6587-6598 (2010)

100. Fan, H., Wang, L., Zhao, K., Li, N., Shi, Z., Ge, Z., Jin, Z.: Fabrication, mechanical properties, and biocompatibility of graphenereinforced chitosan composites. Biomacromol 11(9), 2345-2351 (2010)

101. Qi, W., Xue, Z., Yuan, W., Wang, H.: Layer-by-layer assembled graphene oxide composite films for enhanced mechanical properties and fibroblast cell affinity. J. Mater. Chem. B. 2(3), 325-331 (2014)

102. Park, S.Y., Park, J., Sim, S.H., Sung, M.G., Kim, K.S., Hong, B.H., Hong, S.: Enhanced differentiation of human neural stem cells into neurons on graphene. Adv. Mater. 23, 36 (2011)

103. Kim, J., Park, S., Kim, Y.J., Jeon, C.S., Lim, K.T., Seonwoo, H., Cho, S.-P., Chung, T.D., Choung, P.-H., Choung, Y.-H.: Monolayer graphene-directed growth and neuronal differentiation of mesenchymal stem cells. J. Biomed. Nanotechnol. 11(11), 2024-2033 (2015)

104. Garcia-Alegria, E., Iluit, M., Stefanska, M., Silva, C., Heeg, S., Kimber, S.J., Kouskoff, V., Lacaud, G., Vijayaraghavan, A., Batta, K.: Graphene oxide promotes embryonic stem cell differentiation to haematopoietic lineage. Sci. Rep. 6, 25917 (2016)

105. Tyagi, M., Albert, A., Tyagi, V., Hema, R.: Graphene nanomaterials and applications in bio-medical sciences. World J. Pharm. Pharmacol. Sci. 3(1), 339-345 (2013)

106. Roy, R.K., Lee, K.R.: Biomedical applications of diamond-like carbon coatings: a review. J. Biomed. Mater. Res. B Appl. Biomater. 83(1), 72-84 (2007)

107. Huang, N., Yang, P., Leng, Y., Chen, J., Sun, H., Wang, J., Wang, G., Ding, P., Xi, T., Leng, Y.: Hemocompatibility of titanium oxide films. Biomaterials 24(13), 2177-2187 (2003)

108. Gillespie, W., Frampton, C., Henderson, R., Ryan, P.: The incidence of cancer following total hip replacement. Bone Jt. J. 70(4), 539-542 (1988)

109. Oryan, A., Alidadi, S., Moshiri, A.: Current concerns regarding healing of bone defects. Hard Tissue. 2(2), 1-12 (2013)

110. Rosa, V., Della Bona, A., Cavalcanti, B.N., Nör, J.E.: Tissue engineering: from research to dental clinics. Dent. Mater. 28(4), 341-348 (2012)

111. Amini, A.R., Laurencin, C.T., Nukavarapu, S.P.: Bone tissue engineering: recent advances and challenges. Crit. Rev. Biomed. Eng. 40, 5 (2012)

112. Stevens, M.M.: Biomaterials for bone tissue engineering. Mater. Today 11(5), 18-25 (2008)

113. Lin, L., Chow, K.L., Leng, Y.: Study of hydroxyapatite osteoinductivity with an osteogenic differentiation of mesenchymal stem cells. J. Biomed. Mater. Res. Part A 89(2), 326-335 (2009)

114. Mohandes, F., Salavati-Niasari, M.: In vitro comparative study of pure hydroxyapatite nanorods and novel polyethylene glycol/ graphene oxide/hydroxyapatite nanocomposite. J. Nanopart. Res. 16(9), 2604 (2014)

115. Mohandes, F., Salavati-Niasari, M.: Freeze-drying synthesis, characterization and in vitro bioactivity of chitosan/graphene oxide/hydroxyapatite nanocomposite. RSC Adv. 4(49), 25993 26001 (2014) 
116. Liu, H., Cheng, J., Chen, F., Hou, F., Bai, D., Xi, P., Zeng, Z.: Biomimetic and cell-mediated mineralization of hydroxyapatite by carrageenan functionalized graphene oxide. ACS Appl. Mater. Interfaces. 6(5), 3132-3140 (2014)

117. Liu, Y., Huang, J., Li, H.: Synthesis of hydroxyapatite-reduced graphite oxide nanocomposites for biomedical applications: oriented nucleation and epitaxial growth of hydroxyapatite. J. Mater. Chem. B. 1(13), 1826-1834 (2013)

118. Baradaran, S., Moghaddam, E., Basirun, W.J., Mehrali, M., Sookhakian, M., Hamdi, M., Moghaddam, M.N., Alias, Y.: Mechanical properties and biomedical applications of a nanotube hydroxyapatite-reduced graphene oxide composite. Carbon 69, 32-45 (2014)

119. Nair, M., Nancy, D., Krishnan, A.G., Anjusree, G., Vadukumpully, S., Nair, S.V.: Graphene oxide nanoflakes incorporated gelatin-hydroxyapatite scaffolds enhance osteogenic differentiation of human mesenchymal stem cells. Nanotechnology. 26(16), 161001 (2015)

120. Xie, H., Cao, T., Rodríguez-Lozano, F.J., Luong-Van, E.K., Rosa, V.: Graphene for the development of the next-generation of biocomposites for dental and medical applications. Dent. Mater. 33(7), 765-774 (2017)

121. Gao, C., Liu, T., Shuai, C., Peng, S.: Enhancement mechanisms of graphene in nano-58S bioactive glass scaffold: mechanical and biological performance. Sci. Rep. 4, 4712 (2014)

122. Li, Z., Khun, N.W., Tang, X.-Z., Liu, E., Khor, K.A.: Mechanical, tribological and biological properties of novel 45S5 Bioglass ${ }^{\circledR}$ composites reinforced with in situ reduced graphene oxide. J. Mech. Behav. Biomed. Mater. 65, 77-89 (2017)

123. Walker, L.S., Marotto, V.R., Rafiee, M.A., Koratkar, N., Corral, E.L.: Toughening in graphene ceramic composites. ACS Nano 5(4), 3182-3190 (2011)

124. Lee, J.H., Shin, Y.C., Jin, O.S., Kang, S.H., Hwang, Y.-S., Park, J.-C., Hong, S.W., Han, D.-W.: Reduced graphene oxide-coated hydroxyapatite composites stimulate spontaneous osteogenic differentiation of human mesenchymal stem cells. Nanoscale. 7(27), $11642-11651$ (2015)

125. Xie, H., Cao, T., Gomes, J.V., Neto, A.N.H.C., Rosa, V.: Two and three-dimensional graphene substrates to magnify osteogenic differentiation of periodontal ligament stem cells. Carbon 93, 266-275 (2015)

126. Wu, C., Xia, L., Han, P., Xu, M., Fang, B., Wang, J., Chang, J., Xiao, Y.: Graphene-oxide-modified $\beta$-tricalcium phosphate bioceramics stimulate in vitro and in vivo osteogenesis. Carbon 93, 116-129 (2015)

127. Lee, J.H., Shin, Y.C., Lee, S.-M., Jin, O.S., Kang, S.H., Hong, S.W., Jeong, C.-M., Huh, J.B., Han, D.-W.: Enhanced osteogenesis by reduced graphene oxide/hydroxyapatite nanocomposites. Sci. Rep. 5, 18833 (2015)

128. Rosa, V., Zhang, Z., Grande, R., Nör, J.: Dental pulp tissue engineering in full-length human root canals. J. Dent. Res. 92(11), 970-975 (2013)

129. Gunatillake, P.A., Adhikari, R.: Biodegradable synthetic polymers for tissue engineering. Eur. Cells Mater. 5(1), 1-16 (2003)

130. Agrawal, C.M., Ray, R.B.: Biodegradable polymeric scaffolds for musculoskeletal tissue engineering. J. Biomed. Mater. Res. 55(2), 141-150 (2001)

131. Podila, R., Moore, T., Alexis, F., Rao, A.: Graphene coatings for biomedical implants. J. Vis. Exp. 2013, 73 (2013)

132. Shradhanjali, A., Bouzid, T., Sinitskii, A., Lim, J.Y.: Graphene for dental implant applications. Interfaces. 7(36), 19876-19881 (2017)

133. Segerström, S., Ruyter, I.E.: Adhesion properties in systems of laminated pigmented polymers, carbon-graphite fiber composite framework and titanium surfaces in implant suprastructures. Dent. Mater. 25(9), 1169-1177 (2009)
134. Bartolo, P., Kruth, J.-P., Silva, J., Levy, G., Malshe, A., Rajurkar, K., Mitsuishi, M., Ciurana, J., Leu, M.: Biomedical production of implants by additive electro-chemical and physical processes. CIRP Ann. Manuf. Technol. 61(2), 635-655 (2012)

135. Yang, K., Feng, L., Shi, X., Liu, Z.: Nano-graphene in biomedicine: theranostic applications. Chem. Soc. Rev. 42(2), 530-547 (2013)

136. Li, M., Yang, X., Ren, J., Qu, K., Qu, X.: Using graphene oxide high near-infrared absorbance for photothermal treatment of Alzheimer's disease. Adv. Mater. 24(13), 1722-1728 (2012)

137. Yao, B., Wu, Y., Yu, C., He, J., Rao, Y., Gong, Y., Fu, F., Chen, Y., Li, Y.: Partially reduced graphene oxide based FRET on fiberoptic interferometer for biochemical detection. Sci. Rep. 6, 23706 (2016)

138. Zhang, W., Guo, Z., Huang, D., Liu, Z., Guo, X., Zhong, H.: Synergistic effect of chemo-photothermal therapy using PEGylated graphene oxide. Biomaterials 32(33), 8555-8561 (2011)

139. Su, S., Wang, J., Wei, J., Martínez-Zaguilán, R., Qiu, J., Wang, S.: Efficient photothermal therapy of brain cancer through porphyrin functionalized graphene oxide. New J. Chem. 39(7), 5743-5749 (2015)

140. You, J., Zhang, R., Xiong, C., Zhong, M., Melancon, M., Gupta, S., Nick, A.M., Sood, A.K., Li, C.: Effective photothermal chemotherapy using doxorubicin-loaded gold nanospheres that target EphB4 receptors in tumors. Can. Res. 72(18), 4777-4786 (2012)

141. Yang, Y., Asiri, A.M., Tang, Z., Du, D., Lin, Y.: Graphene based materials for biomedical applications. Mater. Today 16(10), 365373 (2013)

142. Zhou, L., Wang, W., Tang, J., Zhou, J.H., Jiang, H.J., Shen, J.: Graphene oxide noncovalent photosensitizer and its anticancer activity in vitro. Chem. A Eur. J. 17(43), 12084-12091 (2011)

143. Kong, X., Huang, Y.: Applications of graphene in mass spectrometry. J. Nanosci. Nanotechnol. 14(7), 4719-4732 (2014)

144. Tang, L.A.L., Wang, J., Loh, K.P.: Graphene-based SELDI probe with ultrahigh extraction and sensitivity for DNA oligomer. J. Am. Chem. Soc. 132(32), 10976-10977 (2010)

145. Zhou, X., Wei, Y., He, Q., Boey, F., Zhang, Q., Zhang, H.: Reduced graphene oxide films used as matrix of MALDI-TOFMS for detection of octachlorodibenzo-p-dioxin. Chem. Commun. 46(37), 6974-6976 (2010)

146. Lu, M., Lai, Y., Chen, G., Cai, Z.: Matrix interference-free method for the analysis of small molecules by using negative ion laser desorption/ionization on graphene flakes. Anal. Chem. 83(8), 3161-3169 (2011)

147. Zhang, S., Ding, L., Li, S., Kong, X., Huang, Y.: Use of graphene as a matrix to minimize reduction in the process of matrixassisted laser desorption/ionization. Rapid Commun. Mass Spectrom. 27(11), 1278-1282 (2013)

148. Luo, Y.-B., Shi, Z.-G., Gao, Q., Feng, Y.-Q.: Magnetic retrieval of graphene: extraction of sulfonamide antibiotics from environmental water samples. J. Chromatogr. A 1218(10), 1353-1358 (2011)

149. Lu, J., Wang, M., Li, Y., Deng, C.: Facile synthesis of $\mathrm{TiO}_{2}$ /graphene composites for selective enrichment of phosphopeptides. Nanoscale. 4(5), 1577-1580 (2012)

150. Kim, Y.-K., Min, D.-H.: Durable large-area thin films of graphene/carbon nanotube double layers as a transparent electrode. Langmuir 25(19), 11302-11306 (2009)

151. Kim, Y.-K., Min, D.-H.: Preparation of the hybrid film of poly (allylamine hydrochloride)-functionalized graphene oxide and gold nanoparticle and its application for laser-induced desorption/ionization of small molecules. Langmuir 28(9), 4453-4458 (2012)

152. Lee, J., Kim, Y.-K., Min, D.-H.: Laser desorption/ionization mass spectrometric assay for phospholipase activity based on graphene 
oxide/carbon nanotube double-layer films. J. Am. Chem. Soc. 132(42), 14714-14717 (2010)

153. Kim, Y.-K., Na, H.-K., Kwack, S.-J., Ryoo, S.-R., Lee, Y., Hong, S., Hong, S., Jeong, Y., Min, D.-H.: Synergistic effect of graphene oxide/MWCNT films in laser desorption/ionization mass spectrometry of small molecules and tissue imaging. ACS Nano 5(6), 4550-4561 (2011)

154. Kim, Y.-K., Min, D.-H.: Fabrication of alternating multilayer films of graphene oxide and carbon nanotube and its application in mechanistic study of laser desorption/ionization of small molecules. ACS Appl. Mater. Interfaces. 4(4), 2088-2095 (2012)

155. Qian, K., Zhou, L., Liu, J., Yang, J., Xu, H., Yu, M., Nouwens, A., Zou, J., Monteiro, M.J., Yu, C.: Laser engineered graphene paper for mass spectrometry imaging. Sci. Rep. 3, 1415 (2013)

156. Cheng, G., Wang, Z.-G., Liu, Y.-L., Zhang, J.-L., Sun, D.-H., Ni, J.-Z.: A graphene-based multifunctional affinity probe for selective capture and sequential identification of different biomarkers from biosamples. Chem. Commun. 48(82), 10240-10242 (2012)

157. Liu, Q., Shi, J., Sun, J., Wang, T., Zeng, L., Jiang, G.: Graphene and graphene oxide sheets supported on silica as versatile and high-performance adsorbents for solid-phase extraction. Angew. Chem. 123(26), 6035-6039 (2011)
158. Shi, C., Meng, J., Deng, C.: Enrichment and detection of small molecules using magnetic graphene as an adsorbent and a novel matrix of MALDI-TOF-MS. Chem. Commun. 48(18), 2418$2420(2012)$

159. Zou, X., Zhang, L., Wang, Z., Luo, Y.: Mechanisms of the antimicrobial activities of graphene materials. J. Am. Chem. Soc. 138(7), 2064-2077 (2016)

160. Chen, J., Peng, H., Wang, X., Shao, F., Yuan, Z., Han, H.: Graphene oxide exhibits broad-spectrum antimicrobial activity against bacterial phytopathogens and fungal conidia by intertwining and membrane perturbation. Nanoscale. 6(3), 1879-1889 (2014)

161. Solís-Fernández, P., Bissett, M., Ago, H.: Synthesis, structure and applications of graphene-based 2D heterostructures. Chem. Soc. Rev. 46(15), 4572-4613 (2017)

Publisher's Note Springer Nature remains neutral with regard to jurisdictional claims in published maps and institutional affiliations. 